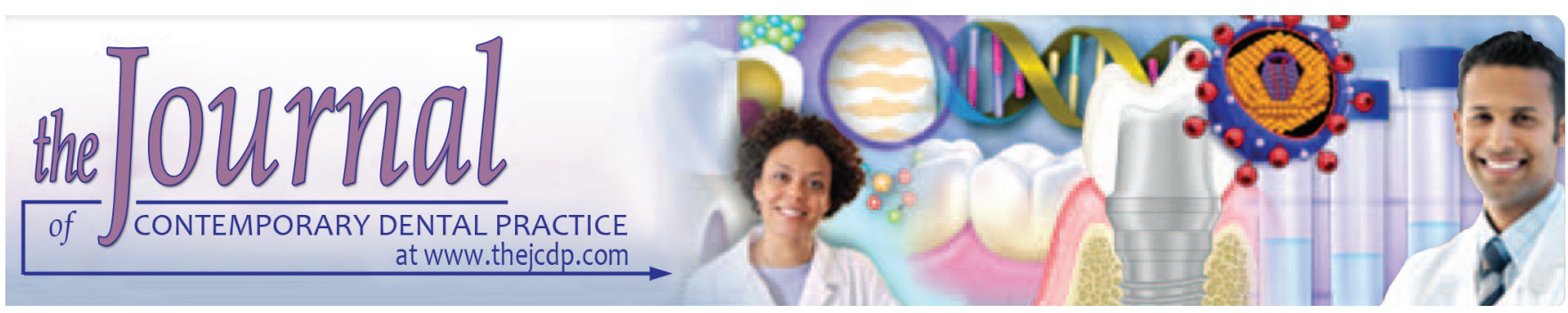

\title{
Tooth Wear Patterns among Khat and Shammah Users in Jazan City, Kingdom of Saudi Arabia: A Cross-sectional Survey
}

\author{
${ }^{1}$ Mohammed E Sayed, ${ }^{2}$ Ammar D Hamdi, ${ }^{3}$ Bassam M Hakami, ${ }^{4}$ Maryam H Mugri, ${ }^{5}$ Shilpa H Bhandi
}

\begin{abstract}
Aim: The effect of Khat and Shammah habits, with the parafunctional jaw activities that accompany them, on the structure and integrity of the natural dentition has not yet been investigated. The literature lacks studies that identify the patterns of tooth wear among Khat and Shammah users. Therefore, this study is the first attempt to address this concern in Jazan City population, Kingdom of Saudi Arabia.
\end{abstract}

Materials and methods: A cross-sectional survey study was conducted among 300 recruits among dental clinics in Jazan City, Kingdom of Saudi Arabia from October 1, 2015, to April 30, 2016. Questionnaires were used for data collection on oral habits (Khat and Shammah use), age, gender, intake of acidic food or beverages, food habits (intake of fruits, grains, and vegetables), systemic diseases, oral hygiene habits (brushing frequency, technique, and type of toothbrush), parafunctional habits, stress, and acid reflux. Clinical examination was performed to assess the grade of tooth wear. Bivariate analysis was performed to determine the empirical relationship between the independent variables and outcomes. In addition, binary logistic regressions were used to measure the relationship between the independent variables and each of the dependent variables (presence of occlusal wear, tooth wear grade 0 through 4 ).

Results: Khat and Shammah use was statistically significantly associated with tooth wear $(p<0.05)$. A significant association

\footnotetext{
${ }^{1}$ Department of Restorative Dentistry, Rutgers School of Dental Medicine, Newark, New Jersey, USA; Department of Prosthetic Dental Sciences, College of Dentistry, Jazan University, Jazan Kingdom of Saudi Arabia

${ }^{2,3}$ Department of Prosthetic Dental Sciences, College of Dentistry, Jazan University, Jazan, Kingdom of Saudi Arabia

${ }^{4}$ Department of Preventive Dental Sciences, College of Dentistry Jazan University, Jazan, Kingdom of Saudi Arabia

${ }^{5}$ Department of Restorative Dental Sciences, College of Dentistry, Jazan University, Jazan, Kingdom of Saudi Arabia

Corresponding Author: Mohammed E Sayed, Department of Restorative Dentistry, Rutgers School of Dental Medicine Newark, New Jersey, USA, Phone: +12014062039, e-mail: drsayed203@gmail.com
}

of tooth wear was observed with age, gender, intake of acidic food and beverages, oral hygiene habits, and stress.

Conclusion: Consumption of Khat and Shammah may be attributed as one of the major reasons associated with tooth wear among the Saudi population.

Clinical significance: The habitual use of Khat and Shammah causes tooth wear of varying severity, which may negatively affect esthetics, phonetics, and function and necessitate a complex restorative treatment.

Keywords: Khat, Saudi population, Shammah, Tooth wear.

How to cite this article: Sayed ME, Hamdi AD, Hakami BM, Mugri $\mathrm{MH}$, Bhandi SH. Tooth Wear Patterns among Khat and Shammah Users in Jazan City, Kingdom of Saudi Arabia: A Crosssectional Survey. J Contemp Dent Pract 2017;18(6):429-436.

Source of support: Nil

Conflict of interest: None

\section{INTRODUCTION}

Wear can be defined as the progressive loss of material from the contacting surfaces of a body, caused by relative motion at the surface. ${ }^{1,2}$ Tooth wear is a complex, multifactorial phenomenon with the interplay of biological, mechanical, chemical, and anthropological factors. ${ }^{2,3}$

It has been recognized that tooth wear is a clinical problem, i.e., becoming increasingly important in the aging population. ${ }^{2,4,5}$ This may be due to an increasing dental awareness, with increased interest in retaining teeth as opposed to having them extracted. ${ }^{6}$ The terms attrition, abrasion, abfraction, and erosion have been used interchangeably to describe the loss of tooth structure and dental biomaterials. ${ }^{2}$ These terms, however, are not in themselves descriptive of the wear process, nor do they imply the causative factor, but instead describe clinical manifestations of some underlying events. ${ }^{7}$ The generalized severe loss of occlusal tooth structure is associated with loss of vertical dimension 
of occlusion and subsequent disruption of esthetics, phonetics, and function. ${ }^{8}$ The outcome of this process often necessitates extensive restorative rehabilitation of the worn dentition as a valuable component of the stomatognathic system. ${ }^{8}$

The Khat plant (Catha edulis) is produced in certain areas of East Africa and the Arabian peninsula, and the leaves are chewed for their stimulating effect. Fresh material, which is preferred by users, contains a substance that rapidly converted to norpseudoephedrine. ${ }^{9,10}$ As a consequence of the traditional means of consumption, intoxication with Khat is self-limiting, but chronic consumption can cause certain disturbances to the health of the user and may also lead to social and economic damage to the individual and the community. ${ }^{11,12}$

Shammah is a preparation of smokeless tobacco, being a mixture of powdered tobacco, carbonate of lime, ash, black pepper, oils, and flavouring agents. Shammah is placed in the mouth as a quid. The sites of Shammah retention in the oral cavity have been reported to include the buccal cavity, the lingual vestibule of the mouth, the gingivobuccal sulcus, the lower labial, or buccal vestibules. ${ }^{13,14}$ The use of smokeless tobacco in Kingdom of Saudi Arabia is most frequently observed in Jazan province, although it is not restricted to this province. ${ }^{13}$

Khat has a very complex alkaloid composition. Cathedulins, for example, comprise one group of alkaloids with up to 62 members. ${ }^{15,16}$ Khat also contains vitamin $C$ and tannins as well as small amounts of essential oils, sterols, triterpenes, thiamine, riboflavin, niacin, iron, and amino acids. ${ }^{15,17}$ Despite the extensive literature about Khat chewing, information concerning its effects on oral health is inadequate. Few studies have investigated the effects of Khat chewing on oral hygiene, dentition, periodontium, oral mucosa, temporomandibular joint, integrity and success of dental restorations, and prostheses, suggesting detrimental effects of variable degrees across these parameters. ${ }^{15,18-27}$ On the contrary, few studies have reported low caries prevalence among Khat chewers. ${ }^{17,20}$ During a Khat-chewing session, the oral cavity is exposed for several hours to the various chemicals that are extracted from Khat by saliva. The physical/mechanical and chemical effect of Khat and Shammah use, and other habits that accompany them, on the integrity of the tooth structure needs to be elucidated. Therefore, this study is the first attempt to investigate the relation between tooth wear presence or severity and the use of Khat and Shammah among users. The null hypothesis of the present study stated that there would be no association between tooth wear presence or severity and the use of Khat and Shammah among users in comparison to nonusers.

\section{MATERIALS AND METHODS}

\section{Data Collection}

A cross-sectional survey study was conducted to investigate the relation between tooth wear patterns among Khat and Shammah users in Jazan City, Kingdom of Saudi Arabia. Data collection was done from October 1, 2015, to April 30, 2016. A convenient sample size of 300 Khat and Shammah users was included in the study. All subjects with severe malocclusion and congenital malformations of teeth were excluded from the study. Assistance from the local health and education authority was sought for recruitment of the study participants. All subjects were informed about the study in a language of their comprehension, and voluntary written informed consent was obtained from them. Ethical clearance for conducting the study was obtained from the Institutional Review Board at Jazan University College of Dentistry. The study proforma (questionnaire and exam chart) was pretested and validated before the study through a pilot study. Cronbach's alpha value of 0.89 showed good internal consistency of the study tool. Informed consent was obtained from participants after having been properly educated about the objectives of the study and the confidentiality of data. Questionnaires were used for data collection on oral habits (Khat and Shammah use), age, gender, intake of acidic food or beverages, food habits (intake of fruits, grains, and vegetables), systemic diseases, oral hygiene habits (brushing frequency, technique, and type of toothbrush), parafunctional habits, stress, and acid reflux.

The intraoral examination was conducted to assess for tooth wear. An ordinal scale ${ }^{28,29}$ was used for grading the severity of occlusal wear. Table 1 shows the criteria used to grade the tooth wear severity in the present study. This examination was performed using a tongue depressor for tissue retraction, mouth mirror for indirect vision, guaze for drying the oral mucosa under adequate illumination using natural and dental unit light. The intraoral examination was conducted by two dentists who were trained

Table 1: Criteria for grading the degree of tooth wear ${ }^{28,29}$

\begin{tabular}{ll}
\hline Grades & Degree of occlusal wear \\
\hline 0 & $\begin{array}{l}\text { No visible facets in enamel, occlusal/incisal morphology } \\
\text { intact }\end{array}$ \\
I & $\begin{array}{l}\text { Marked wear facets in enamel occlusal/incisal } \\
\text { morphology altered }\end{array}$ \\
II $\quad$ Wear into dentin, dentin exposed occlusally/incisally \\
and/or adjacent tooth surface, occlusal/incisal \\
morphology changed in shape with height reduction of \\
tooth \\
III $\quad \begin{array}{l}\text { Extensive wear into dentin, larger dentin area (>2 mm) } \\
\text { exposed occlusally/incisally and or adjacent tooth } \\
\text { surface, occlusal/incisal morphology totally lost locally } \\
\text { or generally; substantial loss of crown height } \\
\text { IV } \quad \text { Wear into secondary dentin (verified by photographs) }\end{array}$ \\
\hline
\end{tabular}


and calibrated. The training and calibration were done to facilitate the accurate detection of tooth wear and achieve concordance among the examiners respectively. The Kappa statistics value for inter-examiner reliability in this study was 0.95 .

\section{Statistical Analysis}

All data were compiled systematically in Microsoft Excel Worksheet and analyzed using Statistical Package Social Sciences (SPSS version 21, IBM, USA). Descriptive statistics were calculated. Bivariate analysis (Chi-square/ Fisher's exact tests and independent t-tests) was performed to determine the empirical relationship between each independent variable and outcome. In addition, binary logistic regressions were used to measure the relationship between the independent variables and each of the dependent variables: Occlusal wear, tooth wear grades 0, I, II, III, and IV. The independent variables with the p-value that was less than 0.10 from the bivariate analysis were included in the logistic regression. Forward
(Wald) selection procedures were used to obtain the final models. Statistical significance level was set to 0.05 for the logistic regression.

\section{RESULTS}

Table 2 shows the descriptive statistics of independent variables for all outcomes (occlusal wear presence or absence and grade 0 through 3 of tooth wear). A total of 236 participants were finally included in the statistical analysis. No subjects were in tooth wear grade IV, that is why it was not included in the descriptive table and statistical comparisons. Independent variables with p-values $<0.10$ were included in the logistic regression. Oral habits variable was not included in the logistic regression for the outcome variables of occlusal wear presence/absence and occlusal wear grades 0 and III since a quasi-complete separation occurred when they were included in the model. A Z-test was used to compare the proportions of occlusal wear presence among the categories of oral habits with adjusted p-values (Bonferroni method).

Table 2: Descriptive statistics of independent variables for all study outcomes

\begin{tabular}{|c|c|c|c|c|c|c|}
\hline \multirow[b]{2}{*}{$n=236$} & & $\begin{array}{l}\text { Occlusal wear } \\
\text { presence }\end{array}$ & $\begin{array}{l}\text { Tooth wear } \\
\text { grade } 0\end{array}$ & $\begin{array}{l}\text { Tooth wear } \\
\text { grade I }\end{array}$ & $\begin{array}{l}\text { Tooth wear } \\
\text { grade II }\end{array}$ & $\begin{array}{l}\text { Tooth wear } \\
\text { grade III }\end{array}$ \\
\hline & & $\begin{array}{l}n=169 \\
(\%=71.6)\end{array}$ & $\begin{array}{l}n=70 \\
(\%=29.7)\end{array}$ & $\begin{array}{l}n=116 \\
(\%=49.2)\end{array}$ & $\begin{array}{l}n=102 \\
(\%=43.2)\end{array}$ & $\begin{array}{l}n=47 \\
(\%=20.3)\end{array}$ \\
\hline Independent variable & & \multicolumn{5}{|c|}{$n(\%)$} \\
\hline \multirow[t]{5}{*}{ Oral habits } & Khat chewing & $80(98.8)$ & $1(1.2)$ & $61(75.3)$ & $45(55.6)$ & $11(13.6)$ \\
\hline & Shammah & $27(100.0)$ & $0(0.0)$ & $17(63.0)$ & $24(88.9)$ & $11(40.7)$ \\
\hline & Both & $42(97.7)$ & $0(0.0)$ & $19(44.2)$ & $31(72.1)$ & $26(60.5)$ \\
\hline & None & $20(23.5)$ & $69(81.2)$ & $19(44.2)$ & $2(2.4)$ & $0(0.0)$ \\
\hline & $p$-value & $<0.001^{*}$ & $<0.001^{*}$ & $<0.001^{*}$ & $<0.001^{*}$ & $<0.001^{*}$ \\
\hline \multirow[t]{3}{*}{ Gender } & Male & $130(74.7)$ & $46(26.4)$ & $87(50.0)$ & $83(47.7)$ & $38(21.8)$ \\
\hline & Female & 39 (62.9) & $24(38.7)$ & $29(46.8)$ & $19(30.6)$ & $10(16.1)$ \\
\hline & $p$-value & $0.077^{*}$ & $0.069^{*}$ & 0.663 & $0.020^{*}$ & 0.338 \\
\hline \multirow[t]{4}{*}{ Acidic drink } & 0 time/week & $14(50.0)$ & $14(50.0)$ & $5(17.9)$ & $8(28.6)$ & $6(21.4)$ \\
\hline & 1-3 times/week & $108(68.4)$ & $53(33.5)$ & $81(51.3)$ & $67(42.4)$ & $29(18.4)$ \\
\hline & >3 times/week & $47(94.0)$ & $3(6.0)$ & $30(60.0)$ & $8(28.6)$ & $6(21.4)$ \\
\hline & $p$-value & $<0.001^{*}$ & $<0.001^{*}$ & $0.001^{*}$ & $0.088^{*}$ & 0.498 \\
\hline \multirow[t]{4}{*}{ Acidic food } & 0 time/week & $31(52.5)$ & $29(49.2)$ & $20(33.9)$ & $16(27.1)$ & $5(8.5)$ \\
\hline & 1-3 times/week & $88(72.1)$ & $36(29.5)$ & $64(52.5)$ & $63(51.6)$ & $29(23.8)$ \\
\hline & >3 times/week & $50(90.9)$ & $5(9.1)$ & $32(58.2)$ & $23(41.8)$ & $14(25.5)$ \\
\hline & $p$-value & $<0.001^{*}$ & $<0.001^{*}$ & $0.020^{*}$ & $0.007^{\star}$ & $0.032^{*}$ \\
\hline \multirow[t]{4}{*}{ Fruits } & 0 time/week & $23(50.0)$ & $23(50.0)$ & $18(39.1)$ & $8(17.4)$ & $1(2.2)$ \\
\hline & 1-3 times/week & $100(73.5)$ & $39(28.7)$ & $71(52.2)$ & $66(48.5)$ & $30(22.1)$ \\
\hline & $>3$ times /week & $46(85.2)$ & $8(14.8)$ & $27(50.0)$ & 28 (51.9) & $17(31.5)$ \\
\hline & $p$-value & $<0.001^{*}$ & $0.001^{*}$ & 0.306 & $<0.001^{\star}$ & $0.001^{*}$ \\
\hline \multirow[t]{4}{*}{ Grains } & 0 time/week & $26(46.4)$ & $32(57.1)$ & $21(37.5)$ & $6(10.7)$ & $1(1.8)$ \\
\hline & 1-3 times/week & 75 (74.3) & $27(26.7)$ & $55(54.5)$ & $55(54.5)$ & $24(23.8)$ \\
\hline & >3 times /week & $68(86.1)$ & $11(13.9)$ & $40(50.6)$ & $40(51.9)$ & $23(29.1)$ \\
\hline & $p$-value & $<0.001^{*}$ & $<0.001^{*}$ & 0.120 & $<0.001^{*}$ & $<0.001^{\star}$ \\
\hline \multirow[t]{4}{*}{ Vegetables } & 0 time/week & $26(53.1)$ & $25(51.0)$ & $19(38.8)$ & $9(18.4)$ & $2(4.1)$ \\
\hline & 1-3 times/week & $81(73.6)$ & $30(27.3)$ & $58(52.7)$ & $56(50.9)$ & $28(25.5)$ \\
\hline & >3 times/week & $62(80.5)$ & $15(19.5)$ & $39(50.6)$ & $37(48.1)$ & $18(23.4)$ \\
\hline & $\mathrm{p}$-value & $0.003^{*}$ & $0.001^{*}$ & 0.254 & $<0.001^{*}$ & $0.006^{*}$ \\
\hline
\end{tabular}

Cont'd... 


\begin{tabular}{|c|c|c|c|c|c|c|}
\hline & & $\begin{array}{l}\text { Occlusal wear } \\
\text { presence }\end{array}$ & $\begin{array}{l}\text { Tooth wear } \\
\text { grade } 0\end{array}$ & $\begin{array}{l}\text { Tooth wear } \\
\text { grade I }\end{array}$ & $\begin{array}{l}\text { Tooth wear } \\
\text { grade II }\end{array}$ & $\begin{array}{l}\text { Tooth wear } \\
\text { grade III }\end{array}$ \\
\hline$n=236$ & & $\begin{array}{l}n=169 \\
(\%=71.6)\end{array}$ & $\begin{array}{l}n=70 \\
(\%=29.7)\end{array}$ & $\begin{array}{l}n=116 \\
(\%=49.2)\end{array}$ & $\begin{array}{l}n=102 \\
(\%=43.2)\end{array}$ & $\begin{array}{l}n=47 \\
(\%=20.3)\end{array}$ \\
\hline \multicolumn{2}{|l|}{ Independent variable } & \multicolumn{5}{|c|}{$n(\%)$} \\
\hline \multirow[t]{3}{*}{ Systemic disease } & Yes & $39(83.0)$ & $10(21.3)$ & $21(44.7)$ & $22(46.8)$ & $19(40.4)$ \\
\hline & No & $130(68.8)$ & $60(31.7)$ & $95(50.3)$ & $80(42.3)$ & $29(15.3)$ \\
\hline & $p$-value & $0.053^{*}$ & 0.160 & 0.493 & 0.579 & $<0.001^{*}$ \\
\hline \multirow[t]{5}{*}{ Brushing times per day } & 0 time & $93(92.1)$ & $11(10.9)$ & $58(57.4)$ & $65(64.4)$ & $39(38.6)$ \\
\hline & 1 time & $57(64.8)$ & $31(35.2)$ & $44(50.0)$ & $29(33.0)$ & $6(6.8)$ \\
\hline & 2 times & $14(37.8)$ & $23(62.2)$ & $11(29.7)$ & $6(16.2)$ & $2(5.4)$ \\
\hline & $>2$ times & $5(50.0)$ & $5(50.0)$ & $3(30.0)$ & $2(20.0)$ & $1(10.0)$ \\
\hline & $\mathrm{p}$-value & $<0.001^{*}$ & $<0.001^{*}$ & $0.019^{*}$ & $<0.001^{*}$ & $<0.001^{*}$ \\
\hline \multirow[t]{5}{*}{ Brushing technique } & None & $93(92.1)$ & $11(10.9)$ & $58(57.4)$ & $65(64.4)$ & $39(38.6)$ \\
\hline & Vertical & $29(47.5)$ & $32(52.5)$ & $24(39.3)$ & $13(21.3)$ & $4(6.6)$ \\
\hline & Horizontal & $23(60.5)$ & $15(39.5)$ & $17(44.7)$ & $15(39.5)$ & $2(5.3)$ \\
\hline & I do not know & $24(66.7)$ & $12(33.3)$ & $17(47.2)$ & $9(25.0)$ & $3(8.3)$ \\
\hline & $p$-value & $<0.001^{*}$ & $<0.001^{*}$ & 0.141 & $<0.001^{*}$ & $<0.001^{*}$ \\
\hline \multirow[t]{6}{*}{ Toothbrush } & None & $93(92.1)$ & $11(10.9)$ & $58(57.4)$ & $65(64.4)$ & $39(38.6)$ \\
\hline & Soft & $20(36.4)$ & $35(63.6)$ & $17(30.9)$ & $9(16.4)$ & $2(3.6)$ \\
\hline & Medium & $46(69.7)$ & $20(30.3)$ & $35(53.0)$ & $24(36.4)$ & $5(7.6)$ \\
\hline & Hard & 7 (77.8) & $2(22.2)$ & $3(33.3)$ & $4(44.4)$ & $2(22.2)$ \\
\hline & I do not know & $3(60.0)$ & $2(40.0)$ & $3(60.0)$ & $0(0.0)$ & $0(0.0)$ \\
\hline & $p$-value & $<0.001^{*}$ & $<0.001^{*}$ & $0.016^{*}$ & $<0.001^{*}$ & $<0.001^{*}$ \\
\hline \multirow[t]{3}{*}{ Parafunctional habits } & Yes & $21(70.0)$ & $9(30.0)$ & $14(46.7)$ & $10(33.3)$ & $8(26.7)$ \\
\hline & No & $148(71.8)$ & $61(29.6)$ & $102(49.5)$ & $92(44.7)$ & $40(19.4)$ \\
\hline & p-value & 0.834 & 0.965 & 0.771 & 0.242 & 0.357 \\
\hline \multirow[t]{3}{*}{ Stress } & Yes & $13(68.4)$ & $6(31.6)$ & $9(47.4)$ & $4(21.1)$ & $3(15.8)$ \\
\hline & No & 156 (71.9) & $64(29.5)$ & $107(49.3)$ & $98(45.2)$ & $45(20.7)$ \\
\hline & p-value & 0.748 & 0.849 & 0.871 & $0.042^{*}$ & 0.771 \\
\hline \multirow[t]{3}{*}{ Acid reflux } & Yes & $7(70.0)$ & $3(30.0)$ & $4(40.0)$ & $2(20.0)$ & $1(10.0)$ \\
\hline & No & $162(71.7)$ & $67(29.6)$ & $112(49.6)$ & $100(44.2)$ & $47(20.8)$ \\
\hline & $p$-value & 1.000 & 1.000 & 0.749 & 0.194 & 0.692 \\
\hline \multirow[t]{7}{*}{ Age } & $\mathrm{N}$ & Yes: 169 & Yes: 70 & Yes: 116 & Yes: 102 & Yes: 48 \\
\hline & & No: 67 & No: 166 & No: 120 & No: 134 & No: 188 \\
\hline & Mean & Yes: 43.3 & Yes: 32.8 & Yes: 40.4 & Yes: 45.2 & Yes: 51.7 \\
\hline & & No: 31.1 & No: 42.8 & No: 39.3 & No: 35.7 & No: 36.8 \\
\hline & SD & Yes: 13.8 & Yes: 11.4 & Yes: 13.2 & Yes: 12.5 & Yes: 10.3 \\
\hline & & No: 9.6 & No: 13.7 & No: 14.5 & No: 13.5 & No: 13.0 \\
\hline & $\mathrm{p}$-value & $<0.001^{*}$ & $<0.001^{*}$ & 0.542 & $<0.001^{*}$ & $<0.001^{*}$ \\
\hline
\end{tabular}

*Independent variable with $\mathrm{p}$-values $<0.10$ was included in the logistic regression; SD: Standard deviation

Table 3 shows the logistic regression results for the outcome of occlusal wear. Independent variables from bivariate analysis used in the logistic regression were gender, acid drink, acid food, fruits, grains, and vegetables, system disease, brushing times per day, brushing technique, toothbrush, and age. The oral habits variable perfectly predicted the occlusal wear outcome. In addition, the amount of acidic drink and food per week, type of tooth brush, and age were associated with the occlusal wear. The groups who use Khat, Shammah, or both users had a significantly higher percentage of occlusal wear presence than the nonuser group, but there was no significant difference among the Khat, Shammah, and both users.
The predicted odds of occlusal wear presence for those who had acidic drink more than three times per week were 14.7 times the odds for those who did not have any acidic drink per week. Similarly, the predicted odds of occlusal wear presence for those who had acidic food more than three times per week were 6.8 times the odds for those who did not have any acidic food per week. Regarding the effect of toothbrush type, the predicted odds of occlusal wear presence for those who used soft, medium, and those who denied brushing were $0.14,0.01$, and 0.04 times the odds for those who used hard toothbrush respectively. Every year, increase in age is associated with $8 \%$ increase in the predicted odds of occlusal wear presence. 
Tooth Wear Patterns among Khat and Shammah Users in Jazan City, Kingdom of Saudi Arabia

Table 3: Logistic regression results for the outcome of occlusal wear (presence/absence)

\begin{tabular}{lllll}
\hline & & Odds ratio & & \\
\hline Drink frequency/week & 0 time/week & Reference & & \\
& $1-3$ times/week & 3.24 & 0.060 \\
& $>3$ times/week & 14.71 & $0.95-11.07$ & $0.003^{*}$ \\
Food frequency/week & 0 time/week & Reference & $2.54-2.54$ & \\
& $1-3$ times/week & 1.96 & & \\
& $>3$ times/week & 6.79 & $0.77-5.01$ & 0.159 \\
Tooth brush & Hard & Reference & $1.56-29.55$ & $0.011^{*}$ \\
& None & 0.04 & & $<0.001^{*}$ \\
& Soft & 0.14 & $0.01-0.12$ & $<0.001^{*}$ \\
& Medium & 0.01 & $0.05-0.39$ & $0.003^{*}$ \\
Age & I do not know & 0.15 & $0.00-0.22$ & 0.059 \\
\hline
\end{tabular}

*Statistically significantly different at 0.05 significance level; $\mathrm{Cl}$ : Confidence interval

Table 4: Logistic regression results for the outcome of grade I degree of occlusal wear

\begin{tabular}{llllc}
\hline & & Odds ratio & $95 \% \mathrm{Cl}$ & $p$-value \\
\hline Oral habits & None & Reference & & $<0.001^{*}$ \\
& Khat chewing & 9.80 & $4.66-20.58$ & $<0.001^{*}$ \\
& Shammah & 5.77 & $2.20-15.11$ & $0.029^{*}$ \\
Drink frequency/week & Both & 2.46 & $1.10-5.53$ & \\
& 0 time/week & Reference & & \\
& $1-3$ times/week & 4.30 & $1.42-13.01$ & $0.010^{*}$ \\
& $>3$ times/week & 4.07 & $1.20-13.83$ & $0.025^{*}$ \\
\hline
\end{tabular}

*Statistically significantly different at 0.05 significance level; Cl: Confidence interval

The group of Khat, Shammah, or both users had a significantly lower percentage of grade 0 degrees of occlusal wear than the nonusers, but there was no significant difference among the Khat, Shammah, and both users.

Table 4 shows the logistic regression results for the outcome of grade I occlusal wear. The oral habits variable and the amount of acidic drink per week were associated with grade I degree of occlusal wear. The predicted odds of grade I degree of occlusal wear for Khat, Shammah, and both users were 9.8, 5.8, and 2.5 times the odds for those who did not use any of them respectively. The predicted odds of grade I degree of occlusal wear for those who had acidic drink one to three times per week and more than three times per week were 4.3 and 4.1 times the odds for those who did not have any acidic drink per week.
Table 5 shows logistic regression results for the outcome of grade II degree of occlusal wear. The oral habits variable and the amount of acidic food and grains per week were associated with grade II degree of occlusal wear. The predicted odds of grade II degree of occlusal wear for Khat, Shammah, and both users were 73, 350, and 119 times the odds for those who did not use any of them respectively. The predicted odds of grade II degree of occlusal wear for those who had acidic food more than three times per week was 0.12 times the odds for those who did not have any acidic food per week. The predicted odds of grade II degree of occlusal wear for those who had grains one to three times per week and more than three times per week were 20.2 and 19.9 times the odds for those who did not have any grains per week.

Table 5: Logistic regression results for the outcome of grade II degree of occlusal wear

\begin{tabular}{lllll}
\hline & & Odds ratio & $95 \% \mathrm{Cl}$ & $\mathrm{p}$-value \\
\hline Oral habits & None & Reference & & $<.001^{*}$ \\
& Khat chewing & 73.66 & $15.46-351.02$ & $<0.001^{*}$ \\
& Shammah & 349.66 & $47.84-2555.68$ & $<0.001^{*}$ \\
& Both & 118.69 & $23.00-612.48$ & 0.185 \\
Food frequency/week & 0 time/week & Reference & & $0.018^{*}$ \\
& $1-3$ times/week & 0.34 & $0.07-1.67$ & $0.02-0.70$ \\
Grains frequency/week & $>3$ times/week & 0.12 & & $0.001^{*}$ \\
& 0 time/week & Reference & $3.72-109.74$ & $0.001^{*}$ \\
\hline
\end{tabular}

*Statistically significantly different at 0.05 significance level; Cl: Confidence interval 
The groups of Shammah and both (Khat and Shammah) users had a significantly higher percentage of grade III degree of occlusal wear than the group of Khat users, and the group of Khat users had a significantly higher percentage of grade III degree of occlusal wear than the nonuser group. There was no significant difference among the groups of Shammah and both users.

\section{DISCUSSION}

The present study was conducted to identify the patterns of tooth wear among Khat and Shammah users in Jazan City, Kingdom of Saudi Arabia. Additionally, an attempt was made to recognize any association, if any, of independent variables of gender, age, intake of acidic food or beverages, food habits (intake of fruits, grains, and vegetables), systemic diseases, oral hygiene habits (brushing frequency, technique, and type of toothbrush), parafunctional habits, stress, and acid reflux with the various grades of tooth wear in the study participants. An exhaustive literature search has revealed that this is the first attempt to identify tooth wear patterns associated with Khat and Shammah use in the Saudi population. Over the years, several studies have been published on the negative effects of smokeless tobacco, namely Khat and Shammah on general as well as oral health. ${ }^{18-26}$ However, no study reported the effect of the oral habits investigated in the present study on the integrity and structure of the natural dentition and tooth wear patterns.

In the present study, tooth wear of varying degrees was found among Khat and Shammah users when compared with nonusers, and this difference was found to be statistically significant. Khat chewers report high frequency of chronic recurrent subluxation and dislocation of the temporomandibular joint, which may cause parafunctional jaw activities. ${ }^{30}$ Low salivary flow rate, lower salivary $\mathrm{pH}$, and increased viscosity of saliva were reported in Khat chewers, which may further predispose these individuals to increased tooth wear. ${ }^{31}$ The juice of the Khat leaves is composed of various components including alkaloids, carbohydrates, tannins, flavinoids, and vitamins. The vitamin $\mathrm{C}$ hence, produced among these ingredients may contribute to dental erosion due to its acidity. ${ }^{32} \mathrm{Al}-\mathrm{Sharabi}$ et $\mathrm{al}^{33}$ reported the detailed description of Khat use in Yemeni population. It was observed that chewers reported a mean of 14.45 years of Khat use with a mean chewing session duration of $4.22 \pm 1.39$ hours. It has been reported that increased occlusal stress is associated with increased tooth wear. Hill and Gibson observed the effects on oral and dental tissue among Yemeni males with an average age of 35 years who chewed Khat for of 20 years..$^{20}$ They found a generalized attrition and temporomandibular joint pain on the Khat-chewing side compared with the non-Khat chewing side.

Tooth wear of either primary or permanent teeth may be a consequence of abrasion, attrition, or erosion or a combination of the three. The first two are mechanical, but erosion is the irreversible loss of dental hard tissue due to chemical action. ${ }^{34,35}$ It is a complex, multifactorial phenomenon with the interplay of biological, mechanical, chemical, and tribological factors. ${ }^{2,5}$ In the present study, it was observed that age, gender, consumption of acidic foods and beverages, food habits, oral hygiene habits, the presence of systemic diseases, and stress were significantly associated with the varying grades of tooth wear. These findings are consistent with the available studies related to the risk factors associated with tooth wear. In our study, higher degrees of tooth wear were observed in elderly individuals as compared with their younger counterparts. Several studies have demonstrated that both the prevalence and the degree of tooth wear increase with age ${ }^{35-40}$ It is natural for the degree of tooth wear to be proportional to the time of exposure of the teeth to the oral cavity. ${ }^{35}$

The degree of tooth wear has been claimed to be more extensive in men than in women. ${ }^{38-40}$ This finding was further corroborated by the observations in the present study where the number of males exhibiting tooth wear was significantly higher than females. In our study, the predicted odds of the presence of occlusal wear for those who had acidic drink more than three times per week were 14.7 times the odds for those who did not have any acidic drink per week. The same odds were 6.8 times for acidic food intake. The importance of the food composition for the development of incisal/occlusal tooth wear has decreased in modern societies. However, excessive intake of citrus fruits, apples, and beverages with a low $\mathrm{pH}$ has, in several case reports, been ascribed the property of causing a substantial loss of hard tooth substance. ${ }^{34,35,41}$

Improper use of toothbrush along with abrasive brush and toothpaste has been reported to be associated with tooth wear and hypersensitivity. ${ }^{42,43}$ This view is similar to the findings of the present study where the predicted odds of the presence of occlusal wear for those who used soft and medium, and those who denied brushing were $0.14,0.01$, and 0.04 times the odds for those who used hard toothbrush respectively. A comparison of young adults in Sweden and Kingdom of Saudi Arabia showed a greater prevalence and severity of tooth wear in the Saudi sample. It was suggested that harsh environmental and climatic conditions probably account for the Saudi experience of high tooth wear. ${ }^{35,44}$

Although Khat chewing is a popular social habit in the Yemenite, Somalian, and Eastern-African communities in the US, Great Britain, and among the Israeli 
Yemenite population, limited number of studies has discussed the oral mucosal changes associated with Khat chewing. ${ }^{12,17,23-26}$ Most studies have focused on the possible carcinogenic properties of this habit. To the best of the authors' knowledge, no research has focused its attention on the detrimental effects of this habit on tooth wear.

The limitations of the study include the sampling methodology. A convenient sampling methodology was used as identification of Khat and Shammah users is a difficult process because the use of these tobacco products is illegal in Kingdom of Saudi Arabia, ${ }^{13,14}$ hence, many people are uncomfortable in revealing these habits. Due to the fact that this is a cross-sectional study, an association can be made between the risk factors and tooth wear; however, causality cannot be established.

\section{CONCLUSION}

This study is the first attempt to identify the patterns of tooth wear associated with Khat and Shammah use among the Saudi population. Within the limitations of the study, it can be concluded that Khat and Shammah use is associated with tooth wear of varying severity. Therefore, clinicians have the added responsibility to make their patients aware of the detrimental effects of Khat and Shammah use on the structure and integrity of the dentition.

\section{REFERENCES}

1. Ramalho A, Miranda JC. The relationship between wear and dissipated energy in sliding systems. Wear 2006;260:361-367.

2. Mair L, Stolarski T, Vowles R, Lloyd C. Wear: mechanisms, manifestations and measurement. Report of a workshop. J Dent 1996 Jan-Mar;24(1-2):141-148.

3. Mahalick JA, Knap FJ, Weiter EJ. Occlusal wear in prosthodontics. J Am Dent Assoc 1971 Jan;82(1):154-159.

4. Hudson J, Goldstein G, Georgescu M. Enamel wear caused by three different restorative materials. J Prosthet Dent 1995 Dec;74(6):647-654.

5. Zhou Z, Zheng J. Tribology of dental materials: a review. J Phys D: Appl Phys 2008 May;41(11):113001.

6. Jagger D, Harrison A. An in vitro investigation into the wear effects of unglazed, glazed, and polished porcelain on human enamel. J Prosthet Dent 1994 Sep;72(3):320-323.

7. Johansson A, Johansson AK, Omar R, Carlsson GE. Rehabilitation of the worn dentition. J Oral Rehabil 2008 Jul;35(7):548-566.

8. Turner KA, Missirlian DM. Restoration of the extremely worn dentition. J Prosthet Dent 1984 Oct;52(4):467-474.

9. Karawya MS, Elkiey MA, Ghourab MG. A study of the alkaloids of Catha edulis Forsk growing in Egypt. J Pharm Sci UAR 1968;9:147-57.

10. Elkiey MA, Karawya MS, Ghourab MG. Estimation of the alkaloids of Catha edulis forsk growing in Egypt. J Pharm Sci UAR 1968;9:159-169.

11. Halbach H. Medical aspects of the chewing of Khat leaves. Bull World Health Organ 1972;47(1):21-29.
12. Kalix P. Catha edulis, a plant that has amphetamine effects. Pharm World Sci 1996 Apr;18(2):69-73.

13. Alsanosy RM. Smokeless tobacco (Shammah) in Saudi Arabia: a review of its pattern of use, prevalence, and potential role in oral cancer. Asian Pac J Cancer Prev 2014 Aug;15(16): 6477-6483.

14. Allard WF, DeVol EB, Te OB. Smokeless tobacco (Shamma) and oral cancer in Saudi Arabia. Community Dent Oral Epidemiol 1999 Dec;27(6):398-405.

15. Al-Hebshi NN, Nielsen $\varnothing$, Skaug N. In vitro effects of crude Khat extracts on the growth, colonization, and glucosyltransferases of Streptococcus mutans. Acta Odontologica Scandinavica 2005 Jan 1;63(3):136-142.

16. Kite GC, Ismail M, Simmonds MS, Houghton PJ. Use of doubly protonated molecules in the analysis of cathedulins in crude extracts of Khat (Catha edulis) by liquid chromatography/ serial mass spectrometry. Rapid Commun Mass Spectrom 2003 Jun;17(14):1553-1564.

17. Luqman W, Danowski TS. The use of Khat (Catha edulis) in Yemen. Social and medical observations. Ann Intern Med 1976 Aug;85(2):246-249.

18. Ali AA, Al-Sharabi AK, Aguirre JM, Nahas R. A study of 342 oral keratotic white lesions induced by qat chewing among 2500 Yemeni. J Oral Pathol Med 2004 Jul;33(6):368-372.

19. Awange DO, Onyango JF. Oral verrucous carcinoma: report of two cases and review of the literature. East Afr Med J 1993 May;70(5):316-318.

20. Hill CM, Gibson A. The oral and dental effects of q'at chewing. Oral Surg Oral Med Oral Pathol 1987 Apr;63(4):433-436.

21. Jorgensen E, Kaimenyi JT. The status of periodontal health and oral hygiene of Miraa (Catha edulis) chewers. East Afr Med J 1990 Aug;67(8):585-590.

22. Kassie F, Darroudi F, Kundi M, Schulte-Hermann R, Knasmüller S. Khat (Catha edulis) consumption causes genotoxic effects in humans. Int J Cancer 2001 May 1;92(3): 329-332.

23. Macigo FG, Mwaniki DL, Guthua SW. The association between oral leukoplakia and use of tobacco, alcohol and Khat based on relative risks assessment in Kenya. Eur J Oral Sci 1995 Oct;103(5):268-273.

24. Mengel R, Eigenbrodt M, Schünemann T, Florès-de-Jacoby L. Periodontal status of a subject sample of Yemen. J Clin Periodontol 1996 May;23(5):437-443.

25. Nasr AH, Khatri ML. Head and neck squamous cell carcinoma in Hajjah, Yemen. Saudi Med J 2000 Jun;21(6):565-568.

26. Soufi HE, Kameswaran M, Malatani T. Khat and oral cancer. J Laryngol Otol 1991 Aug;105(8):643-645.

27. Sayed ME, Bosly RA, Hakami HA, Mugri MH, Bhandi SH. Patterns of restorative failure among Khat and Shammah users in Jazan City, Kingdom of Saudi Arabia: a cross-sectional survey. J Contemp Dent Pract 2017 Mar 1;18(3):234-240.

28. Johansson A, Haraldson T, Omar R, Kiliaridis S, Carlsson GE. A system for assessing the severity and progression of occlusal tooth wear. J Oral Rehabil 1993 Mar;20(2):125-131.

29. Pigno MA, Hatch JP, Rodrigues-Garcia R, Sakai S, Rugh JD. Severity, distribution, and correlates of occlusal tooth wear in a sample of Mexican-American and European-American adults. Int J Prosthodont 2001 Jan-Feb;14(1):65-70.

30. Pennings EJ, Opperhuizen A, van Amsterdam JG. Risk assessment of Khat use in the Netherlands: a review based on adverse health effects, prevalence, criminal involvement and public order. Regul Toxicol Pharmacol 2008 Dec;52(3):199-207. 
31. Al-Alimi KR, Razak AA, Saub R. Salivary caries parameters: comparative study among Yemeni Khat chewers and nonchewers. J Dent Sci 2014 Dec 31;9(4):328-331.

32. Al-Hebshi NN, Al-Sharabi AK, Shuga-Aldin HM,Al-Haroni M, Ghandour I. Effect of Khat chewing on periodontal pathogens in subgingival biofilm from chronic periodontitis patients. J Ethnopharmacol 2010 Dec 1;132(3):564-569.

33. Al-Sharabi AK, Shuga-Aldin H, Ghandour I, Al-Hebshi NN. Qat chewing as an independent risk factor for periodontitis: a cross-sectional study. Int J Dent 2013 Jan;2013:317640.

34. Pindborg, JJ. Pathology of the dental hard tissues. Copenhagen: Munskgaard; 1970. p. 312-321.

35. Dahl BL, Carlsson GE, Ekfeldt A. Occlusal wear of teeth and restorative materials: a review of classification, etiology, mechanisms of wear, and some aspects of restorative procedures. Acta Odontol Scand 1993 Oct;51(5):299-311.

36. Al-Malik MI, Holt RD, Bedi R, Speight PM. Investigation of an index to measure tooth wear in primary teeth. J Dent 2001 Feb;29(2):103-107.

37. Pollmann L, Berger F, Pollmann B. Age and dental abrasion. Gerodontics 1987 Apr;3(2):94-96.
38. Hugoson A, Bergendal T, Ekfeldt A, Helkimo M. Prevalence and severity of incisal and occlusal tooth wear in an adult Swedish population. Acta Odontol Scand 1988 Oct;46(5):255-265.

39. Seligman DA, Pullinger AG, Solberg WK. The prevalence of dental attrition and its association with factors of age, gender, occlusion and TMJ symptomatology. J Dent Res 1988 Oct; 67(10):1323-1333.

40. Salonen L, Helldén L, Carlsson GE. Prevalence of signs and symptoms of dysfunction in the masticatory system. An epidemiologic study of an adult Swedish population. J Craniomandib Disord 1990 Fall;4(4):241-250.

41. Eccles JD, Jenkins WG. Dental erosion and diet. J Dent 1974 Jul;2(4):153-159.

42. Grippo JO, Simring M, Schreiner S. Attrition, abrasion, corrosion and abfraction revisited: a new perspective on tooth surface lesions. J Am Dent Assoc 2004 Aug;135(8):1109-1118.

43. Litonjua LA, Andreana S, Bush PJ, Cohen RE. Tooth wear: attrition, erosion, and abrasion. Quintessence Int 2003 Jun;34(6):435-446.

44. Johansson A. A cross-cultural study of occlusal tooth wear. Swed Dent J Suppl 1992;86:1-59. 